\title{
Homossexualidades e consumo na cidade de São Paulo: estratégias de jovens homossexuais masculinos moradores da periferia
}

Hamilton Harley Carvalho-Silva

Graduado em Pedagogia

e Mestre em Educação

pela Universidade de São

Paulo.
Resumo: Este artigo expõe parte de uma pesquisa sobre jovens homossexuais na cidade de São Paulo, seus trânsitos entre o subúrbio e as zonas nobres da cidade, quando perfazem um circuito de diversão e sociabilidade. 0 objetivo deste texto é esboçar um panorama sobre a influência de um determinado padrão de consumo e poder econômico sobre gays moradores da periferia da cidade de São Paulo. Pretende ainda explicitar as facilidades e as dificuldades enfrentadas pelos sujeitos, nos percursos por eles realizados, bem como seus limites e estratégias, diante das tentativas de se sentirem incluídos nos círculos gays que adotam tais padrões de consumo. A investigação, de inspiração etnográfica, procurou entrevistar, bem como acompanhar o cotidiano de quatro jovens e observar os ambientes e círculos por eles frequentados. 0 estudo conclui que os jovens gays buscam a inclusão em meios cujos padrões de consumo são mais bem aceitos e respeitados socialmente. Um meio de "proteção" contra a homofobia. Constatou ainda que a pobreza, a origem social dos jovens são entraves a serem superados ou camuflados para que possam ser aceitos nesses círculos. Tal aceitação encontra seu limite na efemeridade dos padrões de consumo que mudam constantemente e na dificuldade mesma de "camuflar" a origem social.

Palavras-chave: Homossexualidade. Jovens homossexuais. Consumo. Identidade. 
Homens e mulheres percebem que muitas das perguntas próprias dos cidadãos (...) recebem suas respostas mais através do consumo privado de bens e dos meios de comunicação de massa do que nas regras abstratas da democracia ou da participação coletiva em espaços públicos. (Néstor Garcia Canclini, Consumidores e cidadãos, 2001)

INTRODUÇÃO

Este texto origina-se de um recorte temático da dissertação de mestrado intitulada "Sociabilidade de jovens homossexuais nas ruas de São Paulo: deslocamentos e fronteiras" defendida em 2009, no campo da Sociologia da Educação. 0 conjunto da pesquisa trata dos jovens homossexuais masculinos na cidade de São Paulo e seus trânsitos entre o subúrbio e as zonas nobres da cidade, que perfazem o circuito de diversão e de sociabilidade gay (CARVALHOSILVA, 2009). 0 objetivo foi esboçar um panorama sobre algumas fronteiras (econômicas e de gênero) que perpassam a questão da homossexualidade de jovens urbanos, moradores da periferia'da cidade de São Paulo.

Foram abordadas as facilidades e as dificuldades enfrentadas pelos sujeitos, os percursos por eles realizados, bem como seus limites e estratégias, formas de inserção social e traços de sociabilidade construídos nos movimentos de circulação pela cidade e na interação com os grupos de homossexuais. Foram realizadas quatro entrevistas em profundidade, feitas observações edescrições de espaços na cidade onde ocorre a chamada "cena gay". Foram também analisados os discursos produzidos nas mídias sobre a homossexualidade e quatro diários ${ }^{2}$ escritos pelos quatro jovens entrevistados. Buscaram-se

\footnotetext{
A expressão periferia é utilizada no sentido que os jovens entrevistados atribuíram ao termo ao longo da pesquisa como uma espécie de categoria nativa para classificação dos territórios e dos sujeitos que os ocupam. Periferia se refere aos bairros e localidades distantes dos núcleos de sociabilidade homossexual, marcados pela ausência de espaços de lazer tolerantes ao público homossexual e de centros sofisticados de consumo. Nos discursos dos jovens, a ideia de centro e periferia recebe outros referenciais interpretativos uma vez que bairros com vasta rede de serviços de consumo, lazer e cultura valorizados pelos homossexuais, mesmo quando fora do Centro, como o caso do bairro dos Jardins e Ibirapuera, são considerados centrais em oposição aos bairros que não oferecem os mesmos serviços.

2 Foi proposta para os entrevistados a construção de um "diário de bordo" que contivesse um "mapa” da Cidade e dos itinerários realizados por eles. Para tanto, após aceitar a tarefa, os jovens receberam um caderno de anotações e foram orientados para, além de usá-lo como um espaço livre de expressão, anotar suas apreciações sobre a cidade destacando os lugares de que gosta e não gosta, sensações vividas em espaços diferentes, descrição dos locais de lazer e sociabilidade, descrição das pessoas, dos costumes, das ruas, enfim, fazer relato de experiências durante aproximadamente um mês. Foram produzidos quatro diários que apresentam pontos de convergência sobre as percepções acerca da cidade, mesmo
} 
evitar formulações generalizantes que, muitas vezes, contribuem para a criação de uma imagem homogênea sobre a homossexualidade. Por essas razões, privilegiaram-se, em grande parte, as interpretações que os próprios jovens estabeleceram sobre suas interações sociais, conflitos, barreiras e estratégias de superação das dificuldades encontradas em relação a sua sexualidade, aceitação, sociabilidade e interação em diferentes grupos.

Neste artigo será apresentado um dos aspectos da pesquisa: o consumo como fator fundamental na sociabilidade de parte dos jovens homossexuais, sobretudo no que diz respeito aos sujeitos da pesquisa. Na primeira parte será apresentado um panorama referente à construção da imagem do homossexual como consumidor de bens e serviços sofisticados, bem como o uso dessa imagem nos processos de aproximação e de afastamento de sujeitos e de preconceitos. Para tanto, são utilizados exemplos dos discursos produzidos nas mídias e das percepções dos jovens entrevistados sobre essa imagem. Na segunda parte, a partir dos relatos dos entrevistados, buscaramse aprofundar a discussão nas percepções e nas estratégias utilizadas por jovens homossexuais da periferia, na constituição de interações com outros sujeitos e grupos homossexuais.

\section{O ESPAÇO DE CIRCULAÇÃO}

Esta parte do texto se destina a explicar o contexto em que as interações gays ocorrem na cidade, reconstruindo brevemente o surgimento da "cena gay urbana”.

Áreas da cidade de São Paulo reconhecidas pela circulação significativa de homossexuais ganharam novos desenhos na construção de uma chamada “cena gay" revelada, a partir dos anos 1990, num perímetro que compreende desde a Praça da República até as imediações do Bairro dos Jardins, tendo como via de fluxo de pedestres especialmente ruas como a Frei Caneca e a Augusta (CARVALHO-SILVA, 2009). James Grenn (2000), ao traçar a história da homossexualidade no séculoXX no Brasil, deu destaque especial para grandes centros urbanos como Rio de Janeiro e São Paulo, revelando os territórios de preferência dos homossexuais urbanos, localizados especialmente nos bairros centrais.

compondo modos bem distintos de escrita. A idéia dos diários surgiu a partir da leitura do texto "Couro imperial: raça, travestismo e o culto da domesticidade", de Anne MacClintok (2003), que utilizou os diários produzidos por Hannah Cullwick como fonte primeira de análise. Vale lembrar que os jovens revelaram-se empolgados com esta proposta e que os diários demonstraram elementos importantes do cotidiano de cada um. 
Parte do trabalho de Green (2000) é orientada para toda a sorte de relações sociais que envolviam homossexuais masculinos, que constituíam suas redes de sociabilidade na região do Vale no Anhangabaú, da Praça da República e do Largo do Arouche. Aponta, ainda, esses locais como um reduto gay em plena expansão (Op. cit.). Seus estudos, de cunho histórico, trataram dos movimentos espaciais que os homossexuais realizaram na cidade de São Paulo no século XX, porém sem trazer à tona questões mais particulares dos sujeitos e dos conflitos entre os grupos. Julio Assis Simões e Isadora Lins França (2005), ao descreverem os espaços de sociabilidade homossexual da cidade avançaram com as observações dos grupos e dos conflitos vividos entre eles, nas descrições sobre a expansão dos territórios gays na capital paulista. Acenam para alguns processos de demarcação de territorialidades, que se diferenciam, sobretudo, por traços de distinção econômica entre os grupos e os sujeitos (Op. cit., p. 317).

Muitos frequentadores da porção gay dessa territorialidade central são rapazes de classes populares, que não moram no Centro e ali se reúnem para tomar cerveja, dançar em algumas das várias boates ou simplesmente buscar possiveis parceiros sexuais, observando o movimento da rua. Com frequência esses rapazes são chamados de "bichas quá-quá", "bichas poc-poc", "bichas um real" - termos pejorativos, quase "categorias de acusação", que pretendem designar o jovem homossexual mais pobre e efeminado, de comportamento espalhafatoso e menos sintonizado com linguagens e hábitos "modernos” de gosto, vestimenta e apresentação corporal.

\section{Heterogeneidade no circuito da “cena gay” em São Paulo}

A observação dos espaços de sociabilidade homossexual na cidade de São Paulo, sejam os guetos fechados ou os espaços de apropriação mais sistêmicos, como determinadas ruas e praças na região central, permite capturar elementos da formação de hábitos e de práticas sociais mais particulares no cotidiano desse grupo (CARVALHO-SILVA, 2009). A observação desses espaços, ainda que preliminar, oferece elementos para a percepção de uma homossexualidade bastante heterogênea, que se contrapõe à imagem de certa homogeneidade desse grupo.

Tal heterogeneidade, em princípio, se dá por características que distinguem os sujeitos e grupos homossexuais. Como demonstrou parte da pesquisa,os modos de ser, de vestir e de se comportar, de exibir os corpos, de falar, de usar gírias ${ }^{3}$, entre tantos outros traços distintivos, são utilizados na caracterização

\footnotetext{
Algumas expressões utilizadas por homossexuais constituem uma linguagem chamada "bajubá" ou "pajubá". Ela incorpora termos de línguas africanas, sobretudo aqueles utilizados no Candomblé. É uma linguagem bastante utilizada pelas travestis, porém, disseminada como gíria entre outros grupos e sujeitos homossexuais.
} 
e na construção de hierarquias dos grupos e sujeitos. Geralmente, nesses grupos, podem-se encontrar subgrupos, que disputam entre si e que se ligam compulsoriamente sob o rótulo de homossexual: são miches; dragues; travestis; ursos; lontras; descolados; cools; poc-poc; barbies; qua-quas; quatilambus; entre outros. Vale dizer que muitos desses sujeitos como dragues, ursos e travestis, por exemplo, buscam afirmar essas identidades dentro desses mesmos grupos e junto à sociedade de modo geral. Já outros grupos como barbies, quá-quá e poc-poc, por exemplo, tendem a recusar tal denominação, que muitas vezes carregam elementos pejorativos, como se verá adiante.

São, portanto, grupos que se distinguem, que fazem questão de marcar suas diferenças e preferências, mas que compartilham, na maioria das vezes, dos mesmos espaços físicos e geográficos da cidade. Adotam, porém, em suas interações sociais, mecanismos de controle da aproximação e de interação entre os sujeitos que compõem cada um desses grupos. Pode-se dizer, nesse sentido, que há uma diversidade homossexual, homossexualidades, nas quais disputas, conflitos e preconceitos culturais, de classe e de gênero são reproduzidos.

\section{A CONDIÇÃO ECONÔMICA: TRAÇOS QUE DISTINGUEM}

Um dos traços que distinguem os homossexuais é a condição econômica exibida pelos sujeitos e os usos que dela eles fazem. Traços que denotam situação econômica podem constituir barreiras de aproximação e fronteiras que distanciam os jovens homossexuais entre si, limitando, desse modo, a construção de redes de solidariedade no interior de um mesmo grupo, características essas já demonstradas em outros estudos sobre os segmentos juvenis metropolitanos (MAGNANI, 2000, 2005). Nos territórios da cidade onde a cena homossexual, ou "cena-gay", ocorre com maior intensidade, a adoção de posturas e códigos compartilhados entre os sujeitos corroboram tendências mais gerais da organização do espaço, fazendo surgir mecanismos de inclusão ou exclusão de seus membros (SIMÕES; FRANÇA, 2005).

Como se verificou no trabalho de campo, o uso de indumentárias caras e de grifes famosas, por exemplo, poderá ser suficiente para delimitar (ou impossibilitar) o contato social entre os sujeitos de um mesmo grupo, ou ainda de diferentes grupos classificados como homossexuais. Esse fato foi observado junto aos entrevistados. Paulo 4 , jovem de 18 anos, morador da periferia da Zona Oeste de São Paulo, um dos jovens sujeitos da pesquisa,

4 Para preservar o anonimato dos entrevistados foram utilizados nomes fictícios 
lembra que os valores atrelados à aparência são definidores dos tipos de relações que se estabelece entre os jovens homossexuais e que diante disso, muitos dos rapazes, sobretudo os que dispõem de poucos recursos financeiros, encontram diferentes estratégias para serem aceitos ou para se "parecerem" com os que estão conectados aos estilos mais globais de consumo: "Você não precisa ser rico e poderoso, importa o que você parece ser. Ninguém se importa em quantas vezes você pagou a calça da Diesel [uma marca cara de grife cultuada por muitos homossexuais]. Importa que você tem uma."

Vale destacar que nas diversas expressões das homossexualidades, à semelhança das demais expressões sociais de outros grupos, verifica-se a existência de estruturas de hierarquia dos sujeitos que os colocam em patamares de inferioridade e superioridade em relação aos outros membros do grupo, a partir da avaliação de uma possível condição econômica mais favorável (MAGNANI,2005). Na maioria das vezes, essa condição, quando de fato favorável, é demonstrada pelos sujeitos em suas estratégias de aproximação com os membros dos diferentes grupos homossexuais. Porém, quando essa condição é desfavorável, ela pode, de algum modo, induzir ao uso de outras estratégias como o "disfarce”, a partir do uso de indumentárias caras que agregariam um tipo de valor aos sujeitos a partir da criação de uma imagem pessoal “desejável”: “importa o que você parece ser”.

Nessa perspectiva, alguns homossexuais encontram no consumo uma das chaves de reconhecimento e de afastamento momentâneo das demonstrações de preconceitos homofóbicos na sociedade de modo geral. Outros sujeitos, por sua vez, encontrariam na demonstração do poder de consumo, valorizada também por muitos segmentos homossexuais, uma das chaves de aceitação dentro do próprio grupo. Essas chaves regulam, em muitos casos, os contatos sociais e, em alguma medida, constituem-se em mecanismo relevante para pautar os debates sobre os direitos dos homossexuais.

Os sujeitos acreditam que ao exibir suas posses e seu poder de compra, quando identificados como homossexuais, seriam mais respeitados socialmente pela sua posição de consumidor. Afastariam, assim, momentaneamente as possibilidades de manifestações homofóbicas explícitas. Os direitos do consumidor, sendo mais bem reconhecidos, mais fáceis de serem exigidos e respeitados socialmente do que os direitos homossexuais encobririam as manifestações homofóbicas, agindo como um tipo de "manto protetor". Soma-se a isso o fato de que há, frequentemente, um senso comum de que homossexuais são valorosos consumidores, o que, não raras vezes, 
escamoteia preconceitos em nome das oportunidades de negócios do chamado "pinkmoney" (dinheiro cor-de-rosa), como demonstram os trechos a seguir:

A seguradora American Life é outra que resolveu apostar no chamado "Pink money" (dinheiro cor-de-rosa). Ela lançou no mês passado o Vida Freedon, o primeiro seguro de vida para casais gays do País. Segundo o diretor da empresa, não há estimativas de quanto a população gay do Brasil movimenta financeiramente. Sabe-se apenas que esse consumidor gasta 30\% a mais em bens de consumo em comparação com um heterossexual de mesma condição social. E justamente nesse mercado promissor e carente que a American Life está de olho. "Claro que quando surgiu a ideia do Vida Freedon, tivemos medo de ficar conhecidos como a seguradora dos gays. Mas isso é bobagem. Vimos que, ao comunicar nosso produto dentro da comunidade, quem é de fora nem fica sabendo", diz o executivo. A aceitação do seguro, segundo ele, foi tão boa que acabou chamando a atenção da Tecnisa Construtora e Incorporadora, uma das maiores do País, que se propôs a dar um ano de seguro para cada casal gay que comprar um de seus apartamentos. "0 que para uns é preconceito, para nos é negócio”, diz o diretor de marketing da construtora. Há três anos, ele convenceu a construtora a investir em peças publicitárias voltadas para o público gay, em sites da comunidade homossexual. Hoje, $12 \%$ das vendas da Tecnisa [...] vêm do público GLS (Gays, Lésbicas e Simpatizantes). Na hora de escolher o acabamento, por exemplo, o casal homossexual gasta 25\% do valor do apartamento, enquanto que os heterossexuais não aplicam mais de $12 \%$. Os gays, segundo Busarello, gostam de banheiras com hidromassagem e mármore carrara italiano. "Não construímos prédios cor-de-rosa. Apenas divulgamos que somos uma empresa que aceita a diversidade". (CUNHA, 2006, grifos meus)

Os trechos acima evidenciam o reconhecimento do homossexual, e do próprio preconceito contra ele, como um "negócio" lucrativo, ao mesmo tempo em que apresentam outras evidências que acenam para o "medo" dessas empresas de possuírem sua imagem vinculada à homossexualidade. A mesma revista, voltada exclusivamente para o mundo dos negócios, semanas antes da 10 ${ }^{\underline{a}}$ Parada do orgulho LGBT, em São Paulo, lançou um caderno especial sobre o "promissor mercado gay". Em um de seus artigos, trouxe a experiência e depoimentos de empresários que "abriram suas portas" para esse "mercado", treinando funcionários para lidar com a "diversidade" do novo público de consumidores:

Diversidade, aliás, é o mote do treinamento promovido por dois dos maiores hotéis de luxo de São Paulo: o Mercure Grand Hotel e o Sofitel. "Nesses cursos mostramos aos funcionários como lidar de forma adequada a situações que fogem da rotina. Atender a um casal de namorados gays, por exemplo,", diz ogerente-geral do Mercure.(CUNHA, 2006, grifos meus)

O reconhecimento dos homossexuais como um segmento que agrega uma população com alto poder aquisitivo, em certa medida, alimenta o imaginário coletivo, muitas vezes reforçado pela opinião disseminada na mídia de um modelo de homossexual rico. A pesquisa corrobora que esse imaginário pode ser adotado e expresso por homossexuais que passam a exibir 
comportamentos ligados à sofisticação dos padrões de vida e aos estilos modernos, como observaram os entrevistados.

Aspectos de uma vida gay confortável e glamorosa, por exemplo, são amplamente difundidos pelas inúmeras propagandas veiculadas nos circuitos gays da cidade, como demonstrou a análise dos conteúdos dos folderes direcionados a essa parcela da população (CARVALHO-SILVA, 2009). A mídia dita especializada para o "público gay" e os panfletos distribuídos na noite nas ruas "badaladas" exaltam padrões de beleza masculina e destacam características atreladas ao poder de compra e ao livre acesso aos bens e serviços, esboçando uma imagem dessa população como detentora de alto poder aquisitivo, conectadas com as elites da moda e com o mundo do turismo.

Uma revista destinada ao público gay intitulada DOM (De Outro Modo), lançada em 2008, no Brasil, traz em suas páginas propagandas ostensivas das mais caras grifes de modas do mundo, anuncia ofertas de pacotes turísticos especiais com atendimento personalizado, sobretudo para a Europa, destaca as casas noturnas e restaurantes mais luxuosos da cidade de São Paulo, entrevista celebridades do mundo gay, e celebra a beleza e perfeição dos corpos desejáveis, fortes e "malhados". Oferece, assim, elementos importantes para a construção de personalidades ideais, ou melhor, modelos ideais ${ }^{5}$. A pesquisa mostra que esse tipo de imagem, não raro, é incorporado pelos jovens que buscam, de algum modo, se aproximar desses padrões estéticos e de estilos de vida, como escreveu um dos jovens em seu diário: “0 dia estava frio e tinha muita gente bonita. Nossa, se eu tivesse a beleza aos padrões que a mídia coloca eu sairia beijando todo mundo, rs... Quem dera, mas realmente as pessoas são belas e a cidade maravilhosa. A vida é bela e o paraíso é um comprimido." (trecho do diário de Gustavo, jovem de 18 anos, morador da periferia da Zona Leste de São Paulo).

A exibição desses padrões por homossexuais nos aponta para a segunda chave: estratégias de aceitação e afastamento dos homossexuais dentro do próprio grupo. De diversos modos, muitos homossexuais percebem que assumir a postura desejada, ser esse consumidor, poderia ser um caminho menos duro para o reconhecimento e respeito público, tanto no interior quanto fora dos grupos homossexuais, pois, como já dito, os direitos do

Em 2007, a Rede Globo de Televisão exibiu a telenovela "Paraíso Tropical”, abordando o drama de um casal gay que enfrentava a dificuldade de explicitar sua relação afetiva entre os colegas de trabalho por medo de ser obrigado a conviver com o preconceito e perder o emprego. Por outro lado, o mesmo casal gozava dos luxos e das vantagens de possuir alto poder aquisitivo, sólida formação acadêmica e prestígio profissional, exibindo, ainda, seu referencial de beleza e padrões estéticos globalizados. 
consumidor estariam mais consolidados globalmente do que os direitos dos homossexuais em nossa sociedade. Essa postura de consumidor é, muitas vezes, percebida pelos jovens homossexuais pobres que reconhecem que “(...) tem uma diferenciação econômica muito 'foda'. Eu sairia toda semana, mas não dá. Não tem como se divertir sem grana, ainda mais no mundo gay que o que vale é a grana e a roupa que você veste. 0 cara tem que pagar a droga dele, o taxi dele, a bebida dele. Tem que pagar pra ser aceito." (Depoimento de Paulo, jovem de 18 anos, morador da periferia da Zona Oeste de São Paulo).

Os jovens participantes da pesquisa percebem que, ao tentar se aproximar de alguns grupos homossexuais entram nas lógicas de classificação dos indivíduos. Grupos e sujeitos considerados efeminados, pobres, ligados às redes de prostituição, moradores da periferia, estariam sujeitos a maiores constrangimentos, pois não configurariam nos quadros dos consumidores sofisticados. Estariam, assim, expostos às discriminações sociais mais gerais adensadas pelas discriminações por parte dos homossexuais com maiores poderes aquisitivos, como revela um dos entrevistados ao falar de suas dificuldades em estabelecer interações afetivas com outros homossexuais. Kevin contou que para sair à noite ele precisava se arrumar, se "vestir bem", "tinha que descolar dinheiro para comprar roupa de marca, para não parecer que vinha da favela". Como contou, caso Kevin saísse de "qualquer jeito" iriam logo perguntar o que ele fazia ali. Kevin finaliza o depoimento com uma pergunta que não foi respondida:

(...) tio, você acha que algum dos seus amigos iriam querer namorar comigo se eu dissesse que moro na favela? É só falar que eu moro na favela que 'os truta' sai correndo ou pergunta se eu tenho canal [de drogas]. (depoimento do jovem Kevin, jovem de 18 anos, morador de uma favela da periferia da Zona Oeste de São Paulo).

ESTRATÉGIAS DE APROXIMAÇÃO: ENTRE O “PARECER SER” E A EXCLUSÃO

Quando os jovens percebem que a lógica da hierarquização dos sujeitos tem como principal critério a exibição de determinado status social, lançam mão de estratégias, na maioria das vezes mal sucedidas, de aproximação com os grupos homossexuais. Buscam tornar-se, de modo inconsciente, mercadorias, que possam ser desejadas e também consumidas (BAUMAN, 2008). Tais estratégias e seus resultados serão apresentados adiante.

Os espaços freqüentados pelos gays se distinguem não só por ostentar a bandeira $\mathrm{LGBTT}^{6}$, mas por determinar que o poder de compra e de consumo é

Sigla utilizada para identificar todas as orientações sexuais consideradas minoritárias e manifestações de identidade de gênero. LGBTT refere-se a lésbicas, gays, bissexuais, travestis, transexuais e transgêneros. 
definidor do perfil de seus freqüentadores. Encontrei jovens que disputavam um lugar nas redes de sociabilidade homossexual, assimilando lentamente algumas regras de algo que chamei de um "jogo dentro-fora”, inspirado num depoimento de um dos jovens entrevistados. Nesse jogo, os de dentro são aqueles que podem consumir os serviços oferecidos por casas noturnas, bares e restaurantes caros destinados, na maioria das vezes, ao público gay e, nesses espaços, exibir suas posses e estilos. Os de fora, por sua vez, são aqueles que desejam participar das interações vivenciadas pelos de dentro, porém sem gozar de recursos financeiros suficientes e, portanto, sem grandes chances de manter esse tipo de sociabilidade por muito tempo.

Como se verá, os de fora ainda criam algumas estratégias para atender, em parte os desejos dos de dentro, compartilhando conjuntos (in)comuns de símbolos e códigos, como o vestuário, por exemplo. Tais estratégias permitem certa aproximação, porém, logo se experimenta o afastamento dos grupos e sujeitos a partir da adoção de uma série de classificações, que associam diferentes características individuais à afiliação de classe, cultura, consumo, gostos pessoais e escolhas particulares, como em parte foram anunciadas anteriormente. Nesse sentido, tanto os de dentro como os de fora podem se construir como sujeitos através do consumo e da exibição de suas posses, construindo subjetivações:

O mundo construído de objetos duráveis foi substituído pelo de produtos disponíveis projetados para imediata obsolescência. Num mundo como esse, as identidades podem ser adotadas e descartadas como uma troca de roupa. O horror da nova situação é que todo diligente trabalho de construção pode mostrar-se inútil; e o fascínio da nova situação, por outro lado, se acha no fato de não estar comprometida por experiências passadas, de nunca ser irrevogavelmente anulada, sempre 'mantendo as opções abertas'. (BAUMAN, 1998, p.112)

Tal subjetivação se configura como um dos códigos de identificação, que são criados e mantidos pelos grupos homossexuais. Tais códigos influenciariam diferentes esferas sociais (pessoais e espaciais) ao mesmo tempo em que são recodificados por elas mesmas (SIMÕES; FRANÇA, 2005). Os espaços de interação homossexual se transformam conforme sua clientela e, ao se transformarem, criam uma espécie de seleção "natural” dos tipos classificados por seu poder de consumo que ali poderão frequentar. São, nesse sentido, criadas fronteiras (in)visíveis que se fecham e se abrem num constante controle de acessos que se impõem para esse ou aquele sujeito. Assim, nesse jogo, pode-se estar ora dentro ora fora. Entretanto, as possibilidades de ser de dentro não é privilégio de todos e, por essa razão, o êxito tornase uma conquista reconhecida ou mérito individual. De diversos modos, particularismos e uma falsa sensação de individualização se confundem com pensamentos e atitudes padronizadas que ligam, dividem e identificam os 
grupos. Tal padronização, na maioria das vezes, se torna critério de avaliação dos sujeitos.

É nessa territorialidade que se encena o jogo de inclusão/ exclusão, dentro/ fora que faz com que a "cena gay", aparentemente definida pela oposição central heterossexualidade/homossexualidade, se revele heterogênea, múltipla e também excludente. Um dos elementos definidores dos mecanismos de exclusão dentro dos grupos é o acesso ao consumo e adoção de estilos considerados modernos e sofisticados. Um dos entrevistados faz uma descrição dos "tipos"

Eu não tento me adaptar. Hoje eu vou aos lugares e não vou vestir daquele jeito, eu sou assim e não vou mudar. Descobri que existe uma discrepância enorme. A galera que vai no Vegas, na Loca, mas que vai na Vieira muda o repertório, gírias, falas, referências culturais. Você diz 'esse tem cara de que vai no Vegas, esse tem cara que vai na Vieira'. Quem vai no Vegas usa roupa de marca, mas é diferente da The Week, a roupa é alternativa. Na Vieira é mais a bicha poc-poc da periferia, vai virar na balada, pois não tem como voltar para casa de madrugada. No Bocage é a galerinha mais novinha que tá começando na carreira agora, é um lugar que tem pouca personalidade. Têm os que frequentam a Paulista, os mais cool que vão ao Espaço Unibanco. Os da Augusta, mais antenados, riponga, mais moderno. A galera dos Jardins são bichas muito chatas que usam as roupas de marca e tal, que o que importa é o quanto você pagou. O centro é muito mais a galera mais pobre, mais estereotipada, que veste calça apertada e vai na Planet e Freedon. Tem também os senhores que são gays, tem os ursos que não valorizam muito o corpo. É isso. Tá vendo esse cara que tá atrás da gente, ele tem jeito que vai ao Vegas, olha a jaqueta dele, o jeans. (depoimento de Paulo, jovem de 18 anos, morador da periferia da Zona Oeste de São Paulo).

Uma parcela dos jovens homossexuais, sobretudo daqueles que ainda não gozam de emancipação financeira e/ ou que residem em regiões distantes do Centro ou caracterizadas como pobres (como se autoclassificamos sujeitos da pesquisa) estão suscetíveis a toda sorte de deboches e constrangimentos, como evidencia a fala de Paulo. No vocabulário utilizado por alguns homossexuais aparecem termos e expressões acusatórias ${ }^{7}$, que classificam de maneira pejorativa os sujeitos, denunciando perfis a serem afastados: os de origem indesejada.

Expressões como "bicha pobre", "bicha de Itaquera" [referência a um dos bairros da periferia de São Paulo], "bicha de lotação" [referência a um dos principais meios de transporte utilizados na periferia], "bicha pocpoc", "bicha pão com ovo", entre tantas outras que compõem os modismos das falas daqueles que pretendem marcar diferenças no campo dos gostos, atitudes e condições sociais e econômicas desfavoráveis. 
O CONSUMO COMO MEIO DE TRANSGREDIR A SITUAÇÃO DE ORIGEM: OS LIMITES DO QUE É EFÊMERO

Nos circuitos de sociabilidade homossexual, portanto, não há apenas solidariedade por afiliação de orientação sexual, como poderia se pensar, mas também há forte exclusão decorrente da afiliação de origem socioeconômica e, consequentemente, dos lugares de moradia. Para ter acesso aos espaços e aos circuitos de sociabilidade torna-se, então, necessário fazer uso do direito de consumir. Ter uma vida consumista, que afirma o sujeito no grupo ou, no limite, um objeto passível de ser observado e desejado por outros, poderá ser uma importante marca das possibilidades de interações sociais entre os sujeitos desse grupo.

A lógica de diferenciação é estabelecida a partir das condições que o sujeito tem de, nas palavras de Bauman (1998), se tornar um produto vendável e assim consumível. Ser desejado e alvo de bons comentários e de boa avaliação, como é possível inferir a partir do depoimento de Paulo, anteriormente descrito, pode se tornar uma meta no jogo de dentro-fora para sair da invisibilidade e da posição de desprezo e atrair o olhar do outro. 0 sujeito desejado, portanto, poderá ganhar um ingresso para um mundo sonhado.

(...) o mundo gay tem uma relação estética forte. O cara pode estar 'fodido', mas quer estar numa estética, cabelo cortadinho... Mas eu me vejo destoante, não tenho grande vaidade.

$E$ dai você percebe que as pessoas te olham mais de uma vez. Existe uma discriminação. $O$ pessoal às vezes olha estranho. Daí você já sabe que não vai rolar.(Depoimento de Gustavo, jovem de 18 anos, morador da periferia da Zona Leste de São Paulo)

Mesmo quando o jovem pobre consegue forjar temporariamente sua condição a partir de disfarces visuais dados por suas roupas e aparência (SANTANNA, 2005), como "estar numa estética” segundo relato do jovem, ser percebido nos espaços de sociabilidade gay como morador de regiões e bairros pobres e/ou violentos, poderá gerar uma série de constrangimentos. Os disfarces não podem ser completos, pois, como afirma Bourdieu (2007, p.103), existem maneiras de ser que denunciam a origem social mesmo quando os sujeitos conseguem ocupar por um dado momento patamares que os colocam em posição de igualdade frente ao volume de bens e propriedade:

Ao comparar as práticas de agentes que possuem as mesmas propriedades e ocupam a mesma posição social em determinado momento, mas separados por sua origem, a análise estatística realiza uma operação análoga à percepção comum que, em um grupo, identifica os novos-ricos ou os desclassificados, apoiando-se nos indícios sutis das maneiras de ser ou da postura em que se denuncia o efeito de condições de existência diferente da trajetória modal no grupo considerado.

Dizer onde mora pode ser suficiente para causar frustrações, medos e sofrimento para quem busca afirmação, tolerância e afinidade. Ao contar 
sobre a construção de novas amizades ou busca por parceiros, um dos jovens entrevistados que se esforça para manter uma "aparência desejável" aos homossexuais mais ricos revelou: "[eu] falava que morava no Tatuapé, [pois] quando falava que morava no Itaim [Paulista] melava o esquema" (depoimento do jovem Marcio, de 18 anos, morador da periferia da Zona Leste de São Paulo).

Os estilos de vida celebrados por homossexuais de classes mais favorecidas, além dos referenciais de vestuário, lazer e diversão, pressupõem condições de moradia confortáveis em bairros centralizados e de alto padrão, como evidencia o depoimento do jovem, além da experiência de emancipação familiar e financeira.

As pessoas se aproximariam umas das outras por afinidades. No mundo gay sempre tem as turminhas: as travestis, as que cheiram, as pussycats ${ }^{9}$, as suburbanas... As suburbanas são as que moram afastado do Centro ou da boate. Agora eu voltei para esta classe [suburbana]. Tô morando em Guarulhos ${ }^{10}$. A bicha tem que morar no Centro. A bicha tem que vir pro Centro. A bicha tem que ir para balada. Quem vem pra São Paulo e mora afastado sofre preconceito do mesmo jeito. (Depoimento de Marcio, jovem de 18 anos, morador da periferia da Zona Leste de São Paulo)

Os traços de distinção econômica entre os grupos de homossexuais não se dão apenas pelos territórios ocupados e frequentados. Nesses podemos perceber a celebração de estilos de vida que têm o poder de consumo como regulador de acessos e marcador de diferenças que formam novas fronteiras para aqueles que não dispõem de condições econômicas favoráveis à constituição de modos de vida exaltados por aqueles que gozam de padrões elevados de renda. Essas fronteiras por sua vez não se configuram como uma barreira instransponível, na medida em que existem estratégias para sua transposição, mas não para sua superação (ao menos nesse momento).

A fronteira econômica serve como uma redoma protetora daqueles que buscam distanciamento dos homossexuais mais pobres, conferindo uma falsa solidariedade entre aqueles que pertencem a camadas mais privilegiadas dessa população. Entretanto, estas fronteiras, fazendo uso do termo de Canclini (2003), são “porosas”, ou seja, apresentam brechas e irregularidades que permitem que os de fora, numa combinação de estratégias e desejos,

8 Itaim Paulista e Tatuapé são distritos da Zona Leste de São Paulo. O primeiro está localizado no extremo leste da cidade. É uma região marcada pelos altos índices de pobreza e violência. 0 segundo, trata-se de uma região nobre.

9 Marcio disse que pussycat é o termo usado para designar os homossexuais mais jovens (adolescentes).

10 Município da Grande São Paulo. 
possam, por um período de tempo, participar dos jogos de sedução e aproximação dos de dentro. A porosidade dessas fronteiras possibilita uma passagem para aqueles que abrem mão de alguma solidez em suas identidades transformando-se em “seres líquidos” e adaptáveis às novas condições. Tornar-se um líquido pouco denso, afastando momentaneamente traços da personalidade que podem denunciar um passado-presente pobre, permite que os jovens homossexuais "do lado de fora" da redoma encontrem formas de participar dos jogos estratégicos de afiliação produzidos pelos homossexuais. Umas das estratégias desse jogo, bastante utilizada por Marcio, é: "eu não ando mais em turminhas de gays", afirmou, justificando que no início de suas interações homossexuais os grupos eram importantes para que ele pudesse se firmar como sujeito. No caso dele, as relações mais fluidas deram espaço às escolhas atreladas aos interesses que se objetivavam: “(...) você leva mais em consideração quem você vai agradar. Tem que demonstrar interesse comum, alguma afinidade. Para agradar as pessoas tem que mudar o comportamento. Muda o comportamento, mas não drasticamente." (depoimento de Marcio, jovem de 18 anos, morador da periferia da Zona Leste de São Paulo).

Para Marcio, é possível pertencer a vários grupos ao mesmo tempo, buscando se aproximar de pessoas que tenham um "estilo de vida" próximo daquilo que se busca como ideal. Marcio pontuou, durante a entrevista, que é necessário se parecer com o grupo que deseja participar, mudando, além dos estilos visuais, algumas posturas:

Você passa a se parecer com o grupo. Procura usar as mesmas roupas e ter atitudes que te identificam com o grupo. $O$ jeito de se vestir, o que você bebe. Você vai e vê uma turminha Cult, uma pessoa legal e começa a se inspirar.

Para Paulo, o afastamento de determinados grupos e a proximidade a outros seria uma estratégia de mudar a percepção que as pessoas têm dos sujeitos:

(...) você se afasta dos grupos que não quer ser identificado. Passei a andar com gays emancipados, descolados, sem deixar de andar com outros, mas de forma mais limitada. Eu convivo com pessoas de classe abaixo da minha e não tem problema. Se tem identificação, eu aceito.

As condições de afiliação ao grupo de homossexuais que celebram padrões de vida sofisticados pressupõem, num primeiro momento, entre outras coisas, regras de conduta que têm como forte característica, modos de diversão conectados com padrões globalizados de fruição do tempo livre e modos de vestir conectados com padrões e tendências anunciados pela indústria de moda e estilos. Nesse sentido, os sujeitos poderão ser interpretados, e assim classificados, pelas roupas 
que usam e pelos lugares que frequentam. A possibilidade de sustentação de determinados padrões de consumo define o tipo de acesso que cada sujeito terá aos bens e serviços ofertados aos homossexuais. Alguns bares e casas noturnas, além de fazerem restrições a alguns tipos de vestuário, cobram ingressos considerados caros para grande parte da população $0^{11}$. Nesse sentido, frequentar esse ou aquele lugar também poderá definir quais as relações de sociabilidade serão estabelecidas entre gays, tanto entre os de fora com os de dentro, quanto os de fora e os de dentro entre si.

A capacidade de consumo aparece como um critério importante na definição dos tipos de relações sociais estabelecidas entre homossexuais, relações de aproximação ou "evitação" ${ }^{12}$. Um dos jovens entrevistados, de maneira objetiva, apontou o recurso financeiro disponível como determinante na escolha do local de lazer e diversão, revelando como o dinheiro expresso nos modos e na aparência poderá ser definidor das possibilidades de acesso e interação entre os sujeitos: "Não tem como se divertir sem grana, ainda mais no mundo gay que o que vale é a grana e a roupa que você veste. (...) depende de quanto eu tenho eu escolho a diversão." (depoimento do jovem Gustavo, de 21 anos, morador da periferia da Zona Oeste de São Paulo).

Ao perceber que uma das regras de afiliação é dada pela aparência, os jovens homossexuais mais pobres buscam alternativas para escamotear sua condição econômica e aumentar suas possibilidades de sucesso na travessia de uma das fronteiras. Compreendem que uma das regras do jogo é assumir uma plasticidade que lhes confira certa "hibridação" ${ }^{13}$ a partir da qual não tenham sua imagem imediatamente associada a baixas condições financeiras. Ter a condição social ofuscada pelo uso de roupas caras, por um momento marcado pelo tempo e espaço - período em que compartilha a diversão em bares ou casas noturnas frequentadas por homossexuais mais "endinheirados" e, sobretudo, nas ruas, permite que esses jovens arrisquem novas interações afastando temporariamente o fantasma da discriminação. Vale retomar a fala de um dos jovens: "O mundo gay tem uma relação estética muito forte. $O$ cara pode ${ }^{11}$ No término dessa pesquisa, em 2009, algumas casas noturnas como "The Week", "Flexx" e "Vegas" cobram ingressos que variam de $R \$ 50,00$ a $R \$ 100,00$ dependendo do tipo de festa oferecida.

12 Termo utilizado por Magnani (2005) para definir as relações e critérios de distanciamento entre os grupos.

13 Néstor García Canclini (2003) em um dos seus trabalhos sobre a "hibridación" destaca que um dos aspectos deste fenômeno é a tentativa de relativizar a noção de identidade. Com o estudo dos processos de hibridação podemos localizar as relações de poder existentes na nomeação do mundo. 
estar 'fodido', mas quer estar numa estética, cabelo cortadinho você não precisa ser rico e poderoso, importa o que você parece. Ninguém se importa em quantas vezes você pagou a calça da Diesel. Importa que você tem." (depoimento do jovem Gustavo, de21 anos, morador da periferia da Zona Oeste de São Paulo)

Atravessar uma das fronteiras ostentando determinado vestuário cultuado aumenta as chances de interação dos jovens homossexuais mais pobres ou iniciantes com os mais "descolados", mas também coloca o sujeito frente a outros dilemas. Para manter ou forjar esta aparência aceitável será necessário realizar um esforço de acumular os parcos recursos financeiros, o que não será privilégio de todos, para aquisição de novas indumentárias a fim de evitar as humilhações sociais e as possíveis ridicularizações ${ }^{14}$. Sobre 0 assunto, Kevin de 18 anos, morador da favela na periferia da Zona Oeste de São Paulo afirma: “[eu] tinha que descolar dinheiro para comprar roupa de marca para não parecer que vinha da favela. Caso saísse de qualquer jeito iriam logo perguntar: 'o que você está fazendo aqui?'”.

Dispor de peças do vestuário da moda poderá ser uma estratégia eficaz nas tentativas de aproximação e transposição de algumas fronteiras, mas apenas numa relação superficial e de curto prazo, dado que, na tentativa de estabelecimento de relações mais duradouras, o jovem poderá sofrer novos constrangimentos ao ter sua condição econômica revelada. 0 estabelecimento de relações mais intensas entre os sujeitos, além dos códigos de aparência, poderá exigir a combinação de padrões de consumo de lazer e de diversão que não poderão ser sustentados por jovens homossexuais mais pobres.

Em referência à aparência, a fugacidade dos modismos, característica das sociedades "líquido-modernas", exige uma corrida contra os novos tempos onde o produto consumido se torna obsoleto logo após sair da vitrine devendo, assim, ser substituído por outro ainda mais novo. A permanência no "mundo gay", como incluído, dependeria de diversos fatores para além das condições de moradia e aparência. Seria necessário ter algum tipo de status ou diferenciação frente aos outros. Como afirma Kevin, "Todo gay gosta de marca. Você tem que ter um acessório com etiqueta grande. Você tem que

14 Diversas casas noturnas oferecem pequenos shows conduzidos por draguesqueens que realizam, além de suas performances, pequenas "gincanas" com a participação do público. Nestes espetáculos os sujeitos são convidados a subirem ao palco e recebem uma saraivada de piadas inspiradas pelas características de cada participante. É comum, ou melhor, faz parte do desempenho, que a "espetaculista" faça perguntas sobre o local de moradia dos participantes sem deixar de debochar da resposta dada, insinuando que o sujeito foi de lotação ou caravana. Também faz piadas sobre as roupas que usam e seu tipo físico. Estes shows são considerados momentos altos da noite e parecem agradar aqueles que não são expostos. 
mostrar que tem. Tudo isso prova que você é capaz de comprar, que tem dinheiro. 0 mundo gay é um mundo de aparências. 0 importante é ser bem comentado."

\section{CONSIDERAÇÕES FINAIS}

Na permanente corrida por se tornar um de dentro, os jovens homossexuais mais pobres estão em desvantagem, pois ao buscarem subterfúgios que the confiram alguma igualdade de participação na solidariedade dos de dentro, como o uso de roupas caras, correm o risco de alcançarem esse objetivo demasiadamente tarde, uma vez que os modelos já foram substituídos. Assim, um dos critérios de seleção estabelecidos pelos de dentro para a afiliação de novos membros é o poder de mudar com constância e rapidez, estandose sempre conectados com novas ondas. Aquele que não tem condições de chegar junto aos novos pontos dessa corrida é considerado obsoleto e, portanto, passível de exclusão - ou não desejável. A impossibilidade de consumir com a mesma rapidez exigida poderá ser fator determinante na exclusão e discriminação de uma parcela dos jovens homossexuais.

Os de dentro, nessa lógica, são os que obtiveram êxito tornando-se espécie de mercadorias. Foram bem sucedidos por uma infinidade de fatores e agora possuem o mérito de pertencer ao grupo seleto e contribuir para os arranjos de novas regras e de participar da seleção/exclusão dos que neste grupo pretendem entrar. Os de dentro desejam os outros que também se apresentam como mercadorias desejáveis e visíveis num compartilhamento de códigos comuns. Os de fora, por sua vez, continuam travando uma luta estratégica, travestindo-se dessas mercadorias, sendo algumas vezes exitosos, na tentativa de articular as regras do jogo a seu favor para que em algum momento possam ganhar uma etiqueta que lhes confira valor e status. Despertar o desejo no outro, forjando uma identidade fluida para se tornar algo desejável, é um dos passos para se conseguir um visto de entrada a ser apresentado aos agentes de imigração do mundo dos sonhos. Nessa jogada ser sujeito é ser objeto.

Os jovens que, ao articularem suas estratégias conseguiram o passaporte carimbado aproximando-se dos de dentro, desenham novas estratificações de grupo. Ao conseguirem atravessar a fronteira porosa, mesmo que uma única vez ao mês, esses jovens ganham status de mercadoria de segunda classe que lhes confere certa vantagem frente àqueles que ainda estão na disputa por um lugar no jogo ou que se iniciaram recentemente na corrida. 
As travessias que os colocam temporária e superficialmente, pelo menos na visão dos iniciantes, no patamar dos de dentro não significa fim de jogo e nem afasta o esforço de forjar novas estratégias. Os que ocupam essa posição itinerante logo terão que assimilar outras regras a fim de aumentar e fortalecer as possibilidades de engajamento com os verdadeiramente de dentro e assim permitir que avancem mais uma casa do tabuleiro da vida. Os superficialmente de dentro deverão incorporar os mecanismos de inclusão e exclusão afastando os que tentam atravessar a fronteira. Ser solidário com aqueles que desejam atravessar a fronteira poderá depor contra aquele que, após tanto esforço, conseguiu se aproximar dos de dentro. Qualquer descuido poderá diminuir as chances de êxito na aproximação e estabelecimento de novas relações sociais com os de dentro. Nesse sentido, o jovem que conseguiu atravessar a primeira etapa da fronteira é absorvido pelas regras e passa a excluir os outros, porque uma das regras de afiliação é, justamente, a exclusão. Criam uma política de vida individual e reproduzem a lógica do jogo onde quem não conseguir êxito poderá ficar fadado à depressão e à exclusão.

O desempenho individual é avaliado e a falha só poderá ser atribuída ao indivíduo. Assim como a mercadoria é avaliada individualmente por sua aparência, status e funcionalidade e consumida apenas se atender aos desejos de seus consumidores, os jovens que se aventuram a novas relações de sociabilidade são avaliados. Suas falhas não poderão ser delegadas a nenhum sistema maior. Quem alcança sucesso - ou não - é o sujeito individualmente e a regra é investir na afiliação social de si próprio.

Na medida em que jovens homossexuais de classes desfavorecidas, na busca de espaços mais tolerantes frente à sua sexualidade, são discriminados por sua condição econômica e obrigados a vencer e a transpor os abismos e muros sociais, articulam estratégias de inclusão em grupos homossexuais mais bem aceitos. Porém, a opressão vivenciada pelos mais pobres, nos perímetros gays, não resultanuma ação coletiva de mudança e incorporação de novos membros. Assim, o jovem homossexual de camadas populares poderá ser obrigado a mediar os conflitos vividos de forma individual. 


\section{Homosexuality and consumption in the city of São Paulo: strategies of young homosexual men living in suburban areas}

Abstract: This paper discusses part of a study on young homosexuals in the city of São Paulo - their movements between the suburbs and the city's upscale districts, when they go out to enjoy themselves and partake in social activities. The goal of this text is to outline a panorama regarding the influence of a certain standard of consumption and economic power over gays residing in the outskirts of the city of São Paulo. It also aims to explain the conveniences and hardships faced by these subjects in the movements they make, as well as their limits and strategies in light of their attempts to feel included in gay circles that adopt these standards of consumption. The investigation, inspired by ethnography, sought to interview and follow the day to day lives of four young people, observing the environments and circles that they frequented. The study concludes that young gay men seek inclusion in circles whose standards of consumption are much more accepted and respected socially. A means of "protection" against homophobia. It also found that poverty and the social background of these young men are obstacles to be overcome or obscured in order for them to be accepted in these circles. This acceptance is limited by the fleeting nature of consumption standards, which are constantly changing, and by the very difficulty of “masking” one's social background.

Keywords: Homosexuality. Young homosexuals. Consumption. Identity. 


\section{REFERÊNCIAS}

BAUMAN, Z. 0 mal-estar da pós-modernidade. Rio de Janeiro : Jorge Zahar Editor, 1998.

- Vida para o consumo: a transformação das pessoas em mercadorias. Rio de Janeiro: Jorge Zahar, 2008.

BOURDIEU, P. O espaço social e suas transformações. In: BOURDIEU, P.A distinção: crítica social do julgamento. São Paulo: Edusp, 2007.

CANCLINI, N. G. Noticiasrecientes sobre La hibridación. In: Revista transcultural de música, 2003. Disponível em:http://www.sibetrans.com/trans/trans7/ canclini.htm. Acesso em: 20 de Janeiro de 2013.

CARVALHO-SILVA, H. H.de. Sociabilidades de jovens homossexuais nas ruas de São Paulo: deslocamentos e fronteiras. 2009. 162f. Dissertação (Mestrado em Educação) - Faculdade de Educação da Universidade de São Paulo, São Paulo, 09 de mar de 2009.

CUNHA, L. O poderoso mercado gay: empresas descobrem a força desse milionário segmento, formado por um consumidor que gasta mais que o heterossexual e é fiel às suas marcas. Isto é dinheiro. São Paulo, n. 457, jun. 2006.

GREEN, J. N. Além do carnaval: a homossexualidade masculina no Brasil do século XX. São Paulo: UNESP, 2000.

MCCLINTOCK, A. Couro imperial: raça, travestismo e o culto da domesticidade. Cad. Pagu, n. 20, p. 7-85, 2003.

MAGNANI, J. G. C. e TORRES, L. (Org.). Na Metrópole: Textos de Antropologia Urbana. São Paulo: Edusp, 2000.

. Os circuitos dos jovens urbanos. Tempo Social, São Paulo, v. 17, n.2, p. 173-205, 2005.

SANT'ANNA, D. B. (Org.). Políticas do corpo: elementos para uma história das práticas corporais. São Paulo: Estação Liberdade, 2005.

SIMÕES, J. A. e FRANÇA, I. L. Do "gueto" ao mercado. In: GREEN, James N. e TRINDADE, Ronaldo (Org.). Homossexualismo em São Paulo e outros escritos. São Paulo: UNESP, 2005.

RECEBIDO: Novembro de 2012.

APROVADO: Março de 2013. 